Antonio Espuña, Moisès Graells and Luis Puigjaner (Editors), Proceedings of the $27^{\text {th }}$ European Symposium on Computer Aided Process Engineering - ESCAPE 27

October $1^{\text {st }}-5^{\text {th }}, 2017$,Barcelona, Spain $\odot 2017$ Elsevier B.V. All rights reserved.

\title{
Integration of Bio-refinery Concepts in Oil Refineries
}

\author{
Harvey Arellano-Garcia*, Elham Ketabchi, Tomas Ramirez Reina \\ Department of Chemical and Process Engineering, University of Surrey, Guildford, \\ GU27XH, United Kingdom
}

*h.arellano-garcia@surrey.ac.uk

\begin{abstract}
In this work, the systematic integration of bio-refineries within oil refineries is considered. This is particularly relevant due to the lack of adaptation of existing refineries to diminishing oil supply. Moreover, the integration of oil and bio-refineries has a massively positive effect on the reduction of $\mathrm{CO}_{2}$ emissions. For instance, the biodiesel produced in bio-refineries could be integrated with conventional oil refinery processes to produce fuel, thusly reducing the dependence on crude oil. This represents a suitable alternative for increasing profit margins while being increasingly environmentally friendly. The identified possible routes of integration will be discussed in this contribution. For this purpose, the different proposed alternatives and their configurations were simulated and analysed. The developed models simulated key integrations e.g. a gasification unit that is fed from pyrolysis oil, biodiesel, and refinery residue, before being combined into one system involving all three. Varying forms of synthesis for these three feeds were also considered, focusing on novel techniques as well as environmentally friendly options that made use of waste products from other processes. The simulations revealed valuable gas stream rich in $\mathrm{H}_{2}$, with some $\mathrm{CO}_{2}$ and with a slight excess of $\mathrm{CO}$ resulting from the gasification unit. Further upgrading of these products was achieved by coupling the gasifier with a water gas shift (WGS) unit. This allowed a fine tune of the $\mathrm{H}_{2}: \mathrm{CO}$ ratio in the gas stream which can be further processed to obtain liquid hydrocarbons via Fischer-Tropsch (FT) synthesis or alternatively, clean hydrogen for fuel cells applications.
\end{abstract}

Keywords: Process integration, bio-refinery, oil refinery, GHG, waste reduction.

\section{Introduction}

The key idea is to build the flow sheet of integrated units of a conventional oil refinery with a bio-refinery. The appeal of using a bio-refinery is that the feed stocks are more readily available due to the wide variety of biomass that can be used, i.e. sugar and wood, which produce bio-fuels of comparable quality to fossil fuels and therefore, energy. Furthermore, we have considered the production of bio-diesel from waste water as an extra added-value product (Kiracofe, 2010). The two processes mentioned, along with residue from a conventional refinery are all combined inside a gasification unit to become a feedstock that produces syngas with the use of oxygen and steam. This section of the flow sheeting has been based on the work of Schinski (2014). Once the syngas has been purified, it enters the WGS and FT reactors to produce fuel (liquid hydrocarbon) and hydrogen. Energy obtained from these processes can also be used in a combined heat and power (CHP) unit to maximise the process integration. The tail gas outlet from the FT reactor enters a separation unit, separating the carbon monoxide from the stream. The 
remainder of which, enters the refinery again. Another integration that could be undertaken is the use of raw syngas from the oil refinery into the purifier, mixing it with the syngas derived from the gasification unit, followed then by the WGS and FT reactors.

In this work, the main focus is related to the pyrolysis unit that uses n-butanol to produce oil. The use of this resulting pyrolysis oil is more favourable as a bio-fuel due to the need of mitigating greenhouse gas (GHG) emissions with the use of developing technologies, when compared to conventional fuel. Figure 1 shows the flow sheet used in this work for modelling and simulations in CHEMCAD ${ }^{\mathrm{TM}}$ and Aspen Plus ${ }^{\circledR}$. Moreover, sensitivity analysis was carried out to determine sensible output changes by varying several input properties.

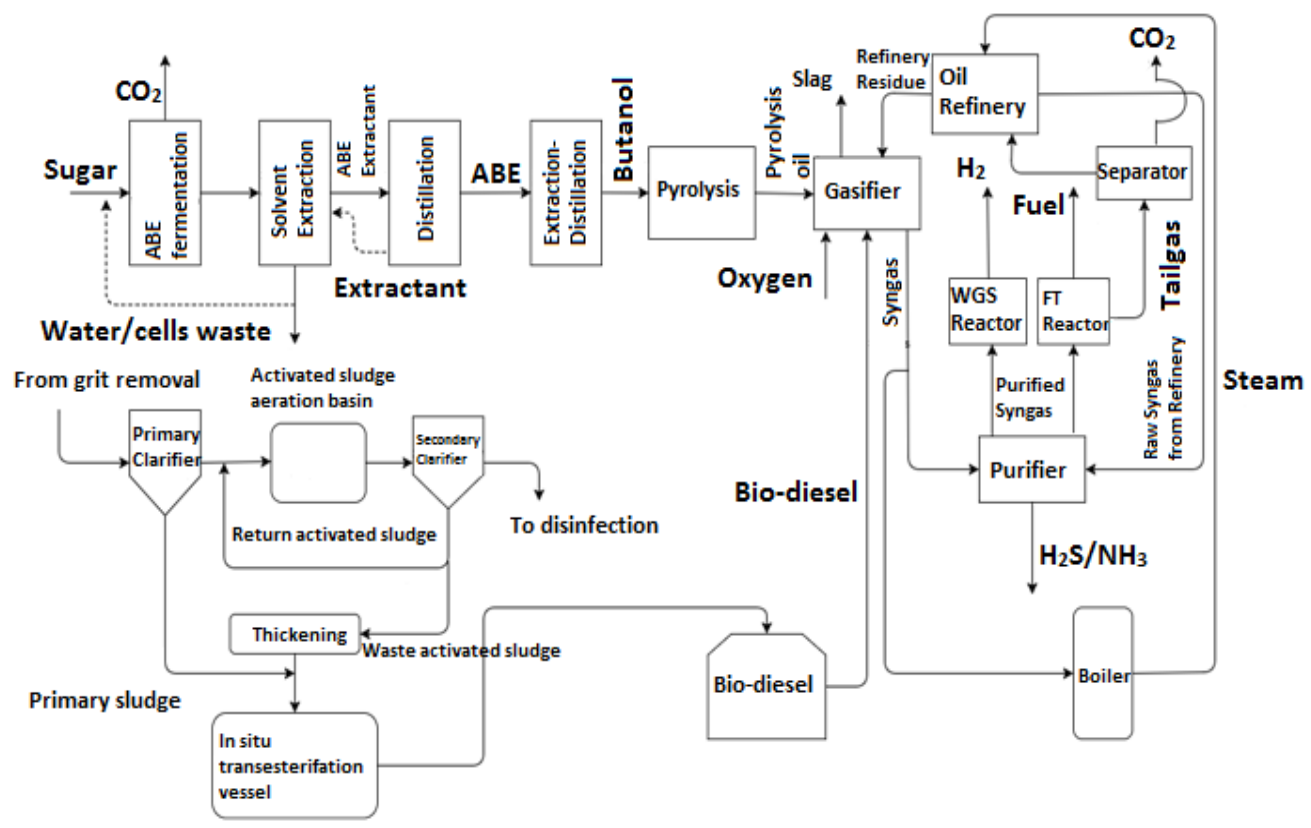

Figure 1. Flow sheet of integrating units: oil refinery and bio-refinery

In the proposed process integration, the first bio-refinery process corresponds to the production of pyrolysis oil. Using sugar as an input to the ABE (acetone-butanol-ethanol) fermentation unit, bacterial species ferment an aqueous sugar solution producing the $\mathrm{ABE}$ mixture with a water immiscible solvent, glyceryl tributyrate, also known as the extractant phase. The next step of the process is the removal of glyceryl tributyrate through conventional distillation, followed by the upgrading of the distilled ABE mixture, which uses a palladium-hydrotalcite (Pd-HT) catalyst to produce a mixture of long chain ketones, that form the reactants for further reactions to produce the types of hydrocarbons found in gasoline, kerosene and diesel (Sreekumar et al., 2015). Butanol has been chosen as the bio-fuel in this process due to its advantages compared to ethanol such as higher energy content and lower vapour pressure. The increase of butanol yields from ABE fermentation are obtained by the application of continuous fermentation and an external distillation process which is illustrated in Figure 1. It has been recommended that the solvent used for this process with a higher efficiency is mesitylene, rather than the 
conventional oleyl alcohol. (Kraemer et al., 2010). Another advantage of butanol is its use as biofuel in vehicles for which no modification is required in the engines. (Nawaz et al., 2011). Once distillation of the ABE mixture has isolated the butanol in the extractive distillation unit, the acetone and ethanol are purified in subsequent distillation, which is not shown in Figure 1. It is worth noting that the butanol undergoes pyrolysis as this pyrolysis oil is better blended with refinery residue and biodiesel.

The other route considered in this flow sheet is the production of bio-diesel, as seen in the bottom of Figure 1, from the waste water sludge that is produced from the waste water treatment process via trans-esterification, then using this bio-diesel as another input for the gasification unit. The waste water sludge is rich in fatty acids, which are the main components required for trans-esterification that produces bio-diesel and glycerol. These two products are easily separated through methods such as gravity settling (Kiracofe, 2010). The biodiesel was considered a viable addition to the two existing feed stocks into the gasifier due to the suitable fuel quality and its further contribution to green energy production.

The gasification unit operating under isothermal and steady state conditions also uses refinery residue, in addition to the bio-diesel and pyrolysis oil, with oxygen and steam to produce syngas, which is the main product, while also producing slag. The use of these three main streams that originate from previously unused material, to create syngas, is to promote more "green" energy production and to offer solutions to dwindling fossil fuel supply.

The conversion of biomass via gasification and hydro-pyrolysis followed by the conversion of natural gas via FT synthesis to liquid fuel is another alternative to these integration pathways proposed by Gencer et al (2014) and we have included it in our integrated approach. The raw syngas from the oil refinery could also be an input of the purifier increasing the amount of syngas entering the WGS and FT reactor. The tail gas produced from the FT reactor could also be entered in a separator, where carbon dioxide from the remainder gas is separated before being returned to the oil refinery. Another aspect of integration proposed is the conversion of syngas to steam via boiling to produce steam for the CHP plant. The output of the boiler being steam could either be directly used in the refinery operations or could be converted to electricity for the benefit of a refinery.

\section{Design and simulation}

\subsection{Mass and energy balance of the gasification unit}

The first step is to identify the specifications of the inputs to the gasification unit being pyrolysis oil, biodiesel, and refinery residue. It is considered that the product of a conventional pyrolysis unit with the efficiency of $20 \%$ is $0.956 \mathrm{~kg} / \mathrm{s}$ using information provided in the work by Desai (2011). The common composition of pyrolysis oil is obtained from Vivarelli and Tondi (2004), which states that it contains $48.5 \mathrm{wt} \%$ carbon, $6.4 \mathrm{wt} \%$ hydrogen and approximately $45 \mathrm{wt} \%$ oxygen. The bio-diesel used as an input in this flow sheet is obtained from the process of using waste from waste water treatment as mentioned before. The values used for this simulation are derived from Kiracofe's 2010 work as well as simple mass and energy balances leading to the values demonstrated in the caption for Fig 2. The composition of bio-diesel chosen for this work is $76.2 \mathrm{wt} \%$ carbon, 12.6 wt $\%$ hydrogen and 11.2 wt\% oxygen (Hoekman et al., 2012). Using the percentage of waste water remaining from the treatment and the conversion rate of 
producing bio-diesel stated in the literature, the flow rate of bio-diesel is calculated to be $1.3 \mathrm{~kg} /$ day (Kiracofe, 2010), the amount of bio-diesel shown here is minimal due to conversion processes only having yields of maximum $13 \%$ as shown in Kiracofe's (2010) research. Considering the input volumes to an oil refinery, we can assume that the outlet volume in the form of refinery residue will be of the order of $1 \times 10^{4} \mathrm{~kg} / \mathrm{h}$. In this case, the refinery residue was initially chosen to be $60,000 \mathrm{~kg} / \mathrm{h}$ for use in the simulation.

According to Medine (2014), the weight percent of carbon, nitrogen, oxygen, sulphur and hydrogen in refinery residue are $85.15 \%, 0.5 \%, 0.055 \%, 4.5 \%$ and $9.3 \%$, respectively. The pressure of the steam required for the gasification of refinery residue is also stated to be 30.8 psig. Standard stoichiometric approaches are not applicable for biomass processes due to the fact that they are not composed of well-defined chemical species, therefore, the amount of oxygen required for the gasification process was derived from the calculation of the empirical formula in (Bernocco et al., 2011). Moreover, through the use of simple energy balance, the temperature of the oxygen and steam mixture required for the gasification unit was calculated.

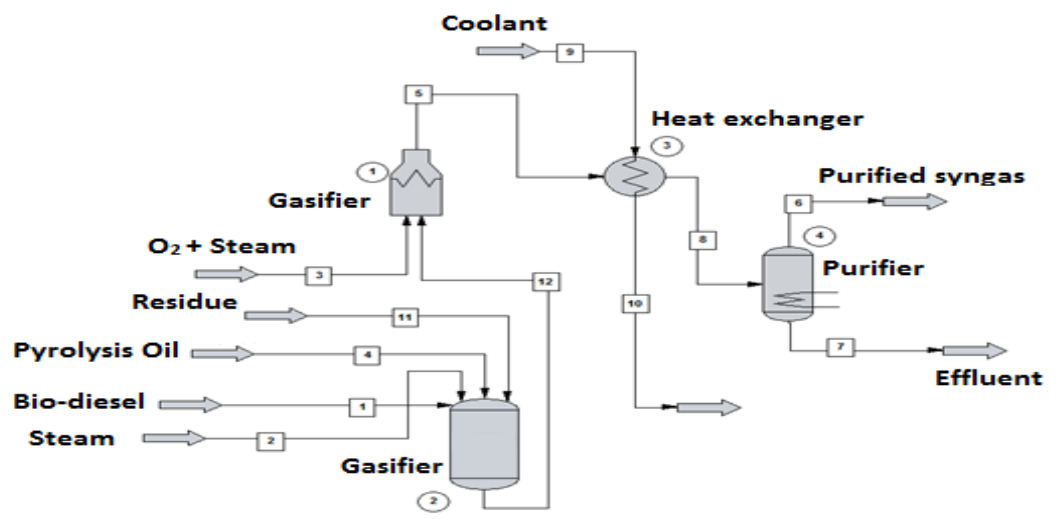

Figure 2. CHEMCAD ${ }^{\mathrm{TM}}$ Version 6.5.5 setup for gasification and purification (gasification conditions: 40 bar, $1400{ }^{\circ} \mathrm{C}$, steam temperature $350{ }^{\circ} \mathrm{C}$ and $99.6 \% \mathrm{O}_{2}$ concentration - adapted from Chao 2015)

The temperature for purifying the produced gas must be decreased to a certain amount as the inputs are not entering the gasification unit individually, therefore a heat exchanger using coolant is required. In this particular case, it is decreased to $120{ }^{\circ} \mathrm{C}$. Depending on the amount of the inlet to the gasification unit, the amount of coolant needed differs. Therefore, as a result of using three inputs, the required coolant flow rate would increase. The simulation was improved, however, by reducing the amount of oxygen for the gasification process in order to obtain higher quality syngas, with a more desirable ratio of $\mathrm{CO}: \mathrm{CO}_{2}$, in favour of $\mathrm{CO}$. 


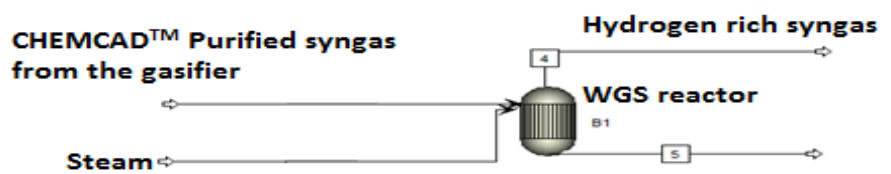

Figure 3. Simulation setup for WGS reaction in Aspen Plus ${ }^{\circledR}$ Version 8.6 (WGS reactor conditions: 36.8 bar, outlet temperature $612{ }^{\circ} \mathrm{C}$, Steam temperature $350{ }^{\circ} \mathrm{C}$, Steam pressure 165 bar - adapted from Kopyscinski et al, 2010)

\subsection{Mass and energy balance of the water gas shift reactor}

Following the gasification modelling (Fig. 1), the next step is the water gas shift reactor. The produced gas or the purified syngas enters the WGS reactor in order to produce hydrogen rich syngas. For this reaction, an equilibrium reactor is selected for the WGS reaction due to the chemistry involved dictating the reliance on equilibrium to favourably produce hydrogen.

\section{Results}

The composition of syngas and WGS reaction products are stated in tables 1 and 2.These values indicate the fact that the syngas produced has high amounts of carbon monoxide followed by hydrogen and carbon dioxide with the percentages of approximately $4 \%, 95$ $\%$, and $1 \%$, respectively. This composition represents the main composition expected for good quality syngas having high amounts of carbon monoxide along with hydrogen and some carbon dioxide, which has been improved even more by conducting sensitivity analyses. It must be noted that the amount of methane produced in the gasification unit were negligible. As can be seen in table 2, the WGS reaction products obtained result in having the desired ratio of 2.0105 being suitable for further processing such as FT reactions.

Table 1.Syngas composition obtained from simulation after improvements made through sensitivity analyses

\begin{tabular}{ccc}
\hline Syngas composition & Amount (kg/h) & Amount (kmol/h) \\
\hline $\mathrm{H}_{2}$ & 3564.34 & 1768.20 \\
\hline $\mathrm{CO}$ & 61817.50 & 2206.98 \\
\hline $\mathrm{CO}_{2}$ & 60.33 & 1.37 \\
\hline
\end{tabular}

Table 2.WGS reaction (WGSR) products derived from simulation

\begin{tabular}{cc}
\hline WGSR Product Composition & Amount (kmol/h) \\
\hline $\mathrm{CO}$ & 1231.06 \\
\hline $\mathrm{H}_{2}$ & 2475.05 \\
\hline $\mathrm{H}_{2} \mathrm{O}$ & 2376.84 \\
\hline $\mathrm{CO}_{2}$ & 827.84 \\
\hline
\end{tabular}




\section{Conclusions}

The results of the simulation showed that the syngas derived from the gasification process show the expected composition of $\mathrm{CO}, \mathrm{H}_{2}$, and $\mathrm{CO}_{2}$ having high amounts of $\mathrm{CO}$. The $\mathrm{H}_{2}$ :CO ratio of the WGSR products expected is also satisfactory, and thus, meeting the requirement for further processing which should be around 0.7. This ratio has been improved through enhancements made in the amount of oxygen, supported by using information obtained through sensitivity analysis. Moreover, changes in composition of the output from the gasification unit were also evaluated by modulating the input flows. Furthermore, through the use of low-value streams and recycled waste, as well as the use of non-fossil based fuels, the proposed process integration drastically reduces the negative environmental impact that the refinery has as well as preventing excessive wastes of energy without increasing costs for advanced equipment or pre-processing. Finally, it could be shown that these integrations will increase the profitability of any refinery that incorporates them properly and effectively while reducing overall refinery wastage.

\section{References}

Bernocco, D., Greppi, P., \& Arato, E. (2011). A novel approach to the biomass pyrolysis step and product lumping. Computer Aided Chemical Engineering (Vol. 29). Elsevier B.V. http://doi.org/10.1016/B978-0-444-53711-9.50023-7

Chao, L. I., Zheng-hua, D. A. I., Ji, Y., Guang-suo, Y. U., \& Fu-chen, W. (2015). Modelling and energy analysis of an integrated coal gasification and pyrolysis system for synthetic natural gas. Journal of Fuel Chemistry and Technology, 43(7), 779-789.

Desai, P. D. (2011). Design of pyrolysis reactor. Retrieved June 28, 2016, from https://www.scribd.com/doc/100920538/Design-of-Pyrolysis-Reactor

Gencer, E., Mallapragada, D., Tawarmalani, M., \& Lafayette, W. (2014). Synergistic Biomass and Natural Gas Conversion to Liquid Fuel with Reduced CO 2 Emissions. In $e$ 8th International Conference on FOCAPD (pp.525-530).

Hoekman, S. K., Broch, A., Robbins, C., Ceniceros, E., \& Natarajan, M. (2012). Review of biodiesel composition, properties, and specifications. Renewable and Sustainable Energy Reviews, 16(1), 143-169.

Kiracofe, N. L. (2010). Converting wastewater treatment facilities into biorefineries: Biodiesel from wastewater microorganisms. University of Delaware.

Kopyscinski, J., Schildhauer, T. J., \& Biollaz, S. M. A. (2010). Production of synthetic natural gas ( SNG ) from coal and dry biomass - A technology review from 1950 to 2009. Fuel, 89(8), $1763-1783$.

Kraemer, K., Harwardt, A., Bronneberg, R., \& Marquardt, W. (2010). Separation of butanol from acetone-butanol- ethanol fermentation by a hybrid extraction- distillation process. Computers \& Chemical Engineering, 35(5), 949-963.

Medine, M. (2014). Residue gasification: an attractive bottom of the barrel upgrading. In New horizons in gasification (p. 17). Rotterdam: Shell.

Nawaz, M., Zondervan, E., \& Gani, R. (2011). Design of an Optimal Biorefinery. Computer Aided Chemical Engineering (Vol. 29). Elsevier B.V.

Schinski, W. L. (2014). Hybrid refinery for co-processing biomass with conventional refinery streams. United states: United states Patent and trademark office.

Sreekumar, S., Baer, Z. C., Pazhamalai, A., Gunbas, G., Grippo, A., Blanch, H. W., Toste, F. D. (2015). Production of an acetone-butanol-ethanol mixture from Clostridium acetobutylicum and its conversion to high-value biofuels. Nature Protocols, 10(3), 528-37.

Vivarelli, S., \& Tondi, G. (2004). Bioenergy for a sustainable development. Chile. 